AMORIM, M.M. et al. Avaliação da qualidade de sementes de Labe labe. PUBVET, Londrina, V. 6, N. 8, Ed. 195, Art. 1307, 2012.

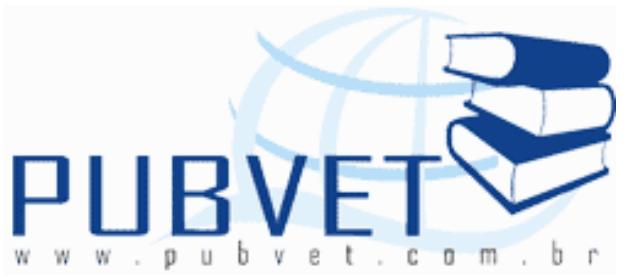

PUBVET, Publicações em Medicina Veterinária e Zootecnia.

\title{
Avaliação da qualidade de sementes de Labe labe
}

\author{
Mariá Moraes Amorim¹ ${ }^{1}$ Bruno Borges Deminicis ${ }^{2}$, Henrique Duarte Vieira ${ }^{3}$, \\ Isabela Moraes Amorim ${ }^{4}$, Guilherme Santos Freitas ${ }^{5}$, Cesar Conte Guimarães \\ Filho $^{2}$, Keithon Damásio Monteiro ${ }^{6}$
}

${ }^{1}$ Zootecnista, Mestranda em Produção Vegetal, Universidade Estadual do Norte Fluminense Darcy Ribeiro. Laboratório de Fitotecnia. Campos dos Goytacazes, RJ, Brasil.

${ }^{2}$ Professor Adjunto, Universidade Federal do Espírito Santo. Departamento de Zootecnia. Alegre, ES, Brasil.

${ }^{3}$ Professor Associado I, Universidade Estadual do Norte Fluminense Darcy Ribeiro. Laboratório de Fitotecnia. Campos dos Goytacazes, RJ, Brasil.

${ }^{4}$ Graduanda em Zootecnia, Universidade Federal do Espírito Santo. Departamento de Zootecnia. Alegre, ES, Brasil.

${ }^{5}$ Zootecnista, Mestrando em Ciências Veterinárias, Universidade Federal do Espírito Santo. Alegre, ES, Brasil.

${ }^{6}$ Zootecnista, Mestrando em Zootecnia na Transição Cerrado Amazônia, Universidade Federal de Mato Grosso. Sinop, MT, Brasil.

\section{Resumo}

O Labe Labe é uma leguminosa potencialmente perene, mas cultivada como anual ou bianual no Brasil, e que possui qualidades que favorecem o seu emprego na alimentação animal, como o elevado teor de proteína bruta e alta 
AMORIM, M.M. et al. Avaliação da qualidade de sementes de Labe labe. PUBVET, Londrina, V. 6, N. 8, Ed. 195, Art. 1307, 2012.

produção de forragem. No entanto, para obter bons resultados, é fundamental que as sementes utilizadas sejam de boa qualidade. São utilizados diversos teste para determinar a qualidade fisiológica de sementes, entre eles se destaca o teste de tetrazólio, por ser rápido e eficiente. Assim, esta revisão teve como objetivo abordar alguns aspectos da utilização de testes de vigor na avaliação da qualidade fisiológica de sementes de Labe Labe.

Palavras-chave: Teste de germinação, Análise de sementes, Fabaceae.

\title{
Evaluation of quality of Dolichos lablab seeds
}

\begin{abstract}
The Dolichos lablab is a perennial legume potentially, but grew as an annual or biannual in Brazil, and it has qualities which favor its use in animal feed, as the high protein content and high forage production. However, to achieve good results, it is essential that the seeds used are of good quality. Several tests are used to determine the physiological seed quality, among them stand out the tetrazolium test, because it is fast and efficient. Thus, this review aimed to address some aspects of the use of vigor tests in the evaluation of physiology quality of Dolichos lablab seeds.
\end{abstract}

Keywords: Germination test, Seed analysis, Fabaceae.

\section{INTRODUÇÃO}

Labe Labe (Dolichos lablab) pertence à família Fabaceae (Leguminosa) e acredita-se que seja originária da Índia, Sudeste Asiático ou África. Atualmente tem sido cultivada e distribuída nos trópicos e subtrópicos (AGANGA e TSHWENYANE, 2003). É muito popular na Índia, sudeste da Ásia, Egito e no Sudão (EVANS, 2002), no Brasil é utilizada principalmente para adubação verde, podendo também ser empregada na alimentação animal.

O seu plantio é feito através de sementes, assim é importante que se conheça o potencial de armazenamento do lote de sementes, pois a 
AMORIM, M.M. et al. Avaliação da qualidade de sementes de Labe labe. PUBVET, Londrina, V. 6, N. 8, Ed. 195, Art. 1307, 2012.

comercialização destes baseia-se, principalmente, no valor cultural dos mesmos. Dos parâmetros de qualidade utilizados para determinação do valor cultural de lotes de sementes, somente a porcentagem de germinação pode sofrer alterações durante 0 período de armazenamento, diminuindo significativamente o valor cultural do lote de sementes (USBERTI, 1982).

O desenvolvimento de testes rápidos visando à determinação da qualidade fisiológica de sementes tem sido um dos principais objetivos dos tecnologistas de sementes há vários anos, principalmente por permitir a tomada de decisão rápida nos programas de controle de qualidade. Dentre esses testes, destaca-se o teste de tetrazólio por possibilitar a avaliação do potencial fisiológico das sementes com rapidez e eficiência quando executado criteriosamente (CERVI e MENDONÇA, 2009).

O teste de tetrazólio reflete a atividade das enzimas desidrogenases, envolvidas no processo de respiração. Pela hidrogenação do 2,3,5 trifenil cloreto de tetrazólio é produzida nas células vivas uma substância vermelha, estável e não difusível, o trifenil formazan. Isto torna possível distinguir as partes vivas, coloridas de vermelho, daquelas mortas que mantêm sua cor (DELOUCHE et al., 1976).

Segundo Oliveira et al. (2005), para a realização do teste, são indicados procedimentos, chamados de pré-condicionamento, como corte, escarificação e embebição em água. Além do pré-condicionamento, é fundamental a utilização de concentração da solução de tetrazólio, tempo e temperatura de condicionamento e avaliação correta da coloração.

Assim esta revisão teve como objetivo abordar alguns aspectos da utilização de testes de vigor na avaliação da qualidade fisiológica de sementes de Labe Labe.

\section{LABE LABE}

Segundo Aganga e Tshwenyane (2003) o primeiro plantio de Labe Labe ocorreu em 1819, quando sementes desta espécie oriundas do Egito foram 
AMORIM, M.M. et al. Avaliação da qualidade de sementes de Labe labe. PUBVET, Londrina, V. 6, N. 8, Ed. 195, Art. 1307, 2012.

plantadas no Jardim Botânico de Sydney, Nova Gales do Sul. Entretanto só após o lançamento do cultivar "Rongai" em 1962, tornou-se amplamente utilizada como forragem na Austrália. Desta forma, o Labe Labe tem sido amplamente distribuido para muitos países tropicais e subtropicais, onde tornou-se naturalizado (AGANGA e TSHWENYANE, 2003).

Segundo Evans (2002) o Labe Labe possui hábito de crescimento volúvel, além de ser ereto, anual ou perene de curta duração, crescendo até um metro de altura, com longas raízes e flores roxas ou brancas. A germinação ocorre geralmente dentro de cinco dias após o semeio (AGANGA e TSHWENYANE, 2003).

O Labe Labe pode ser utilizado na alimentação animal tanto para pastejo quanto na forma de silagem. É a principal cultura forrageira no Kenia, Zimbabue e Sudão. Tem sido também conhecida por seu uso como adubo verde, a adição de matéria orgânica, bem como nitrogênio e minerais no solo (AGANGA e TSHWENYANE, 2003).

\subsection{QUALIDADE DE SEMENTES}

Segundo Alves e Sá (2010) a qualidade da semente utilizada no processo de produção agrícola é um dos principais fatores a ser considerado para a implantação da cultura e há consenso entre os pesquisadores, tecnologistas e produtores de sementes sobre a importância do vigor das sementes e da necessidade de avaliá-lo. Alguns resultados de pesquisa apontam que a baixa qualidade fisiológica de sementes pode resultar em reduções na velocidade de emergência e emergência total, desuniformidade de emergência, menor tamanho inicial de plântulas, produção de matéria seca e na área foliar (HÖFS et al., 2004, KOLCHINSKI et al., 2006).

Existem diferentes testes para análise da qualidade de sementes, o teste de germinação é um deles, e é o mais utilizado, entretanto não proporciona resultados rápidos. Desta forma, é cada vez maior a busca por testes rápidos, sendo o teste de tetrazólio um dos mais utilizados recentemente (OLIVEIRA et 
AMORIM, M.M. et al. Avaliação da qualidade de sementes de Labe labe. PUBVET, Londrina, V. 6, N. 8, Ed. 195, Art. 1307, 2012.

al., 2005; NOVEMBRE et al., 2006; FERREIRA et al., 2007; DIAS e ALVES, 2008; SOUZA et al., 2009; LAMARCA et al, 2009; DEMINICIS et al., 2009; COSTA e SANTOS, 2010).

\subsubsection{Teste de Germinação}

O Teste de germinação tem como objetivo determinar o potencial máximo de germinação de um lote de sementes, o qual pode ser usado para comparar a qualidade de diferentes lotes e também estimar o valor para semeadura em campo. Recomenda-se a utilização como substrato: papel, areia ou água. Os equipamentos necessários são germinadores e contadores de sementes (BRASIL, 2009).

A germinação é afetada por fatores internos e externos; os internos são os intrínsecos da semente, como longevidade e viabilidade; já os fatores externos dizem respeito às condições ambientais, como umidade e temperatura (OLIVEIRA e MEDEIROS FILHO, 2007).

Conhecer as condições que proporcionem germinação rápida e uniforme das sementes é extremamente útil para fins de semeadura. A germinação rápida e o desenvolvimento homogêneo de plântulas reduzem os cuidados por parte dos viveiristas, uma vez que as mudas se desenvolverão mais rapidamente, promovendo um povoamento mais uniforme no campo, onde estarão expostas às condições adversas do ambiente (PACHECO et al., 2006).

\subsubsection{Teste de Tetrazólio}

O principal desafio das pesquisas sobre testes de vigor está na identificação de parâmetros relacionados à deterioração das sementes que precedem a perda da capacidade germinativa. Dessa forma, torna-se importante o uso de testes que possibilitem a deteç̧ão dos estágios iniciais da deterioração, relacionados ao sistema de membranas, atividade enzimática e 
AMORIM, M.M. et al. Avaliação da qualidade de sementes de Labe labe. PUBVET, Londrina, V. 6, N. 8, Ed. 195, Art. 1307, 2012.

redução dos mecanismos energéticos. Dentro deste contexto, destaca-se o teste de tetrazólio (LAMARCA et al., 2009).

De acordo com a Regras para Análise de Sementes (BRASIL, 2009), o Teste de Tetrazólio tem como objetivo determinar rapidamente a viabilidade de sementes, particularmente, daquelas que apresentam dormência, das espécies recalcitrantes e as que germinam lentamente em testes de rotina e determinar a viabilidade das sementes em amostras ou individualmente, quando no final do teste de germinação ocorrer uma alta porcentagem de sementes não germinadas.

O teste de tetrazólio consiste em um método rápido para avaliar a viabilidade e o vigor de sementes, baseando-se na atividade de enzimas do grupo das desidrogenases, presentes nos tecidos vivos. Neste teste, as sementes permanecem em contato com uma solução incolor de cloreto de tetrazólio (2,3,5 trifenil cloreto de tetrazólio), que é absorvida pelos tecidos da semente. Nos tecidos vivos que apresentam atividades respiratória e metabólica normais, as enzimas do grupo das desidrogenases liberam íons hidrogênio $(\mathrm{H}+)$ com os quais o sal 2,3,5 trifenil cloreto de tetrazólio reage, formando um composto insolúvel e estável, de coloração avermelhada, denominado trifenilformazan (DELOUCHE et al., 1976).

A intensidade e localização das partes coloridas e descoloridas são utilizadas para a interpretação do teste. As sementes viáveis tendem a absorver a solução de tetrazólio lentamente, desenvolvendo coloração mais suave do que sementes deterioradas, que adquirem coloração vermelho forte. Os tecidos mortos, nos quais não há atividade dessas enzimas, são caracterizados pela coloração branca, verde ou amarelados e textura flácida (FRANÇA NETO, 1999).

Diversos fatores podem interferir na obtenção de resultados satisfatórios no teste de tetrazólio, principalmente aqueles relacionados à metodologia de execução como preparo das sementes antes da coloração, concentração da solução de tetrazólio, período e temperatura de exposição à solução e critérios de interpretação (OLIVEIRA et al., 2009). 
AMORIM, M.M. et al. Avaliação da qualidade de sementes de Labe labe. PUBVET, Londrina, V. 6, N. 8, Ed. 195, Art. 1307, 2012.

O início do preparo da semente para o teste de tetrazólio é a hidratação dos tecidos. A hidratação da semente facilita o preparo da semente e a absorção da solução de tetrazólio e ativa o sistema enzimático. A absorção de água deve ser lenta para evitar trincas nas sementes ou a lixiviação de substâncias solúveis, principalmente, em sementes deterioradas (CHAMMA e NOVEMBRE, 2007).

O Teste de Tetrazólio tem se mostrado eficiente na avaliação do vigor de sementes de algumas espécies, tais como: canafístula (OLIVEIRA et al., 2005), cunhã (DEMINICIS et al., 2009), pau-brasil (LAMARCA et al., 2009), corezeiro (MENDES et al., 2009), triticale (SOUZA et al., 2010) e leucena (COSTA e SANTOS, 2010).

\section{CONSIDERAÇÕES FINAIS}

O Labe Labe mostra-se com potencial para utilização na alimentação animal, e o uso do teste de tetrazólio para ser uma alternativa interessante na avaliação da qualidade de sementes desta espécie, desde que conduzido de maneira criteriosa.

\section{REFERÊNCIAS}

AGANGA, A.A.; TSHWENYANE, S.O. Lucerne, Lablab and Leucaena leucocephala Forages: Production and Utilization for Livestock Production. Pakistan Journal of Nutrition, Faisalabad, v.2, n.2, p.46-53, 2003.

ALVES, C.Z.; SÁ, M.E. Avaliação do vigor de sementes de rúcula pelo teste de lixiviação de potássio. Revista Brasileira de Sementes, Brasília, v. 32, n.2, p.108-116, 2010.

BRASIL. Ministério da Agricultura, Pecuária e Abastecimento. Regras para análise de sementes. Ministério da Agricultura, Pecuária e Abastecimento. Secretaria de Defesa Agropecuária. Brasília, DF: Mapa/ACS, 2009. 399p.

CERVI, F.; MENDONÇA, E.A.F. Adequação do teste de tetrazólio para sementes de algodoeiro. Revista Brasileira de Sementes, Brasília, v. 31, n.1, p.177-186, 2009.

CHAMMA, H.M.C.P.; NOVEMBRE, A.D.L.C. Teste de tetrazólio para as sementes de milho: períodos de hidratação e de coloração das sementes. Revista Brasileira de Sementes, Brasília, v. 29, n.2, p.125-129, 2007. 
COSTA, C.J.; SANTOS, C.P. Teste de tetrazólio em sementes de leucena. Revista Brasileira de Sementes, Brasília, v.32, n.2, p.066-072, 2010.

DELOUCHE, J.C.; STILL, T.W.; RASPET, M.; LIENHARD, M. 0 teste de tetrazólio para viabilidade da semente. Brasília, DF: AGIPLAN, 1976. 103p.

DEMINICIS, B.B.; VIEIRA, H.D.; SILVA, R.F. Teste de tetrazólio para avaliação da qualidade de sementes de Clitorea ternatea L.. Revista Brasileira de Sementes, Brasília, v.31, n.2, p.054-062, 2009.

DIAS, M.C.L.; ALVES, S.J. Avaliação da viabilidade de sementes de Brachiaria brizantha (Hochst. ex A. Rich) Stapf pelo teste de tetrazólio. Revista Brasileira de Sementes, Brasília, v.30, n.3, p.145-151, 2008.

EVANS, D.O. Sustainable agriculture in Hawaii. Green manures: Legumes. Lablab. http://www2.ctahr.Hawaii.edu/sustainag/SustainableAg/GreenManures/lablab.asp., 2002.

FERREIRA, R.A.; OLIVEIRA, L.M.; TONETTI, O.A.O.; DAVIDE, A.C. Comparação da viabilidade de sementes de Schizolobium parahyba (Vell.) Blake - Leguminosae Caesalpinioideae, pelos testes de germinação e tetrazólio. Revista Brasileira de Sementes, Brasília, v.29, n.3, p.83$89,2007$.

FRANÇA NETO, J.B. Testes de tetrazólio para determinação do vigor de sementes. In: KRZYZANOWSKI, F.C.; VIEIRA, R.D.; FRANÇA NETO, J.B. (Ed.). Vigor de sementes: conceitos e testes. Londrina: ABRATES, 1999. cap. 8, p.1-7.

HÖFS, A.; SCHUCH, L.O.B.; PESKE, S.T.; BARROS, A.C.S.A. Emergência e crescimento de plântulas de arroz em resposta à qualidade fisiológica de sementes. Revista Brasileira de Sementes, Brasília, v.26, n.1, p.92-97, 2004.

KOLCHINSKI, E.M. ; SCHUCH, L.O.B. ; PESKE, S.T. . Crescimento inicial de soja em função do vigor de sementes. Revista Brasileira de Agrociência, Pelotas, v.12, p.163-166, 2006.

LAMARCA, E.V.; LEDUC, S.N.M.; BARBEDO, C.J. Viabilidade e vigor de sementes de Caesalpinia echinata Lam. (pau-brasil - Leguminosae) pelo teste de tetrazólio. Revista Brasileira de Botânica, Água Funda, v.32, n.4, p.793-803, 2009.

MENDES, A.M.S.; BASTOS, A.A.; MELO, M.G.G. Padronização do teste de tetrazólio em sementes de Parkia velutina Benoist (Leguminosae - Mimosoideae). Acta Amazonica, Manaus, v.39, n.4, p.823-828, 2009.

NOVEMBRE, A.D.L.C.; CHAMMA, H.M.C.P.; GOMES, R.B.R. Viabilidade das sementes de braquiária pelo teste de tetrazólio. Revista Brasileira de Sementes, Brasília, v.28, n.2, p.147-151, 2006.

OLIVEIRA, A.B.; MEDEIROS FILHO, S. Influência de tratamentos pré-germinativos, temperatura e luminosidade na germinação de sementes de leucena, cv. Cunningham. Revista Brasileira de Ciências Agrárias. Recife, v.2, n.4, p.268-274, 2007.

OLIVEIRA, C.M.G.; MARTINS, C.C.; NAKAGAWA, J. Método de preparo das sementes de mamoneira (Ricinus communis L.) para o teste de tetrazólio. Revista Brasileira de Sementes, Brasília, v.31, n.1, p.160-167, 2009.

OLIVEIRA, L.M.; CARVALHO, M.L.M.; DAVIDE, A.C. Teste de tetrazólio para avaliação da qualidade de sementes de Peltophorum dubium (Sprengel) Taubert - Leguminosae Caesalpinioideae. Cerne, Lavras, v.11, n.2, p.159-166, 2005. 
PACHECO, M.V.; MATOS, V.P.; FERREIRA, R.L.C; FELICIANO, A.L.P.; PINTO, K.M.S. Efeito de temperaturas e substratos na germinação de sementes de Myracrodruon urundeuva Fr. All. (Anacardiaceae). Revista Árvore, Viçosa-MG, v.30, n.3, p.359-367, 2006.

SOUZA, C.R.; OHLSON, O.C.; GAVAZZA, M.I.A.; PANOBIANCO, M. Tetrazolium test for evaluating triticale seed viability. Revista Brasileira de Sementes, Brasília, v.32, n.3 p.163$169,2010$.

SOUZA, C.R.; OHLSON, O.C.; PANOBIANCO, M. Avaliação da viabilidade de sementes de aveia preta pelo teste de tetrazólio. Revista Brasileira de Sementes, Brasília, v.31, n.3, p.057062, 2009.

USBERTI, R. Teste de envelhecimento acelerado em sementes de capim-colonião. Revista Brasileira de Sementes, Brasília, v.04, n.1, p.23-30, 1982. 